\title{
PERSEPSI DOKTER UMUM DI FASILITAS KESEHATAN TINGKAT PERTAMA KLINIK KIMIA FARMA 125 DENPASAR TENTANG SISTEM KAPITASI BERBASIS PEMENUHAN KOMITMEN PELAYANAN DI ERA JAMINAN KESEHATAN NASIONAL
}

\author{
Coratry Shovariah Premilga*, Rina Listyowati, Putu Ayu Indrayathi \\ Program Studi Kesehatan Masyarakat Fakultas Kedokteran Universitas Udayana \\ *Email: premilgariris@gmail.com
}

\begin{abstract}
ABSTRAK
Sistem kapitasi berbasis pemenuhan komitmen pelayanan yang diatur dalam peraturan BPJS Kesehatan No 2 tahun 2015 mulai diberlakukan per 1 Januari 2017. Adanya perubahan pola pembayaran kapitasi tentunya akan mendapatkan berbagai macam persepsi dokter umum sebagai PPK di FKTP Klinik Kimia Farma 125 Denpasar. Persepsi ini penting untuk diketahui karena akan mempengaruhi perilaku yang akan diberikan oleh dokter umum terhadap pasien JKN. Penelitian ini bertujuan untuk mengetahui efektivitas penyelenggaraan dari sistem kapitasi JKN berbasis pemenuhan komitmen pelayanan. Desain penelitian ini adalah deskriptif kualitatif, dipilih delapan orang dokter umum di Klinik Kimia Farma 125 Denpasar yang ditentukan sesuai kriteria sebagai informan. Penelitian dilakukan pada bulan Mei hingga Juli 2017 bertempat di Klinik Kimia Farma 125 Denpasar. Metode pengambilan data menggunakan metode wawancara mendalam (indepth interview) yang dilakukan selama 20 hingga 40 menit. Hasil penelitian persepsi dokter umum terhadap sistem kapitasi berbasis pemenuhan komitmen pelayanan dimana sebagian besar dokter umum setuju besaran tarif kapitasi yang diberikan oleh BPJS Kesehatan cukup untuk melaksanakan pelayanan kesehatan, sistem kapitasi dirasa dapat meningkatkan kesejahteraan dokter. Standar pelayanan yang diberikan pada era JKN mengikuti standar yang telah diatur oleh BPJS Kesehatan. Dalam pelaksanaannya upaya komitmen pelayanan dilakukan dengan cara menambahkan poli untuk mengurangi waktu antrian. Indikator komitmen pelayanan yang diatur dapat menjadi motivasi untuk meningkatkan mutu pelayanan. Untuk memaksimalkan pemberlakuan sistem kapitasi berbasis pemenuhan komitmen pelayanan, diperlukan upaya tambahan dalam bentuk program promotif dan preventif. BPJS Kesehatan untuk mengelola layanan dan komunikasi dengan dokter diperlukan sosialisasi yang maksimal terhadap program promotif dan preventif untuk meningkatkan kunjungan sehat.
\end{abstract}

Keywords: Persepsi, Kapitasi, Pemenuhan Komitmen Pelayanan

\begin{abstract}
The capitation system based on fulfilling the service commitments regulated in BPJS Kesehatan No 2 tahun 2015 began to take effect as of January 1, 2017. The change in capitation payment patterns will certainly get a variety of perceptions of general practitioners as PPK at FKTP Kimia Farma 125 Denpasar Clinic. This perception is important to know because it will affect the behavior that will be given by general practitioners towards JKN patients. This study aims to determine the effectiveness of the implementation of the JKN capitation system based on fulfilling service commitments. The design of this study was descriptive qualitative, selected eight general practitioners at the Kimia Farma 125 Denpasar Clinic which were determined according to the criteria as informants. The study was conducted in May to July 2017 at the Kimia Farma 125 Clinic in Denpasar. The data collection method uses the in-depth interview method (indepth interview) which is conducted for 20 to 40 minutes. The results of research on the perception of general practitioners of the capitation system based on the fulfillment of service commitments where most general practitioners agree that the amount of the capitation tariff provided by BPJS Health is sufficient to carry out health services, the capitation system is considered to be able to improve the welfare of doctors. Service standards provided in the JKN era followed the standards set by the Health BPJS. In the implementation of the service commitment efforts carried out by adding poly to reduce queuing time. Indicators of service commitment that are set can be a motivation to improve service quality. To maximize the implementation of a capitation system based on fulfilling service commitments, additional efforts are needed in the form of promotive and preventive programs. BPJS Health to manage services and communication with doctors requires maximum socialization of promotive and preventive programs to increase healthy visits.
\end{abstract}

Keywords: Perception, Capitation, Fulfillment of Service Commitments

\section{PENDAHULUAN}

$$
\text { Untuk menyukseskan program }
$$

pemerintah dalam pembiayaan kesehatan, dalam UU No. 40 Tahun 2004, pemerintah bersama Badan Penyelenggara Jaminan Sosial (BPJS) Kesehatan membuat program Sistem
Jaminan Sosial Nasional (SJSN) yaitu Jaminan Kesehatan Nasional (JKN). JKN merupakan suatu sistem asuransi kesehatan sosial yang bersifat wajib di Indonesia, yang dibentuk pada 1 Januari 2014. BPJS Kesehatan akan membayar kepada FKTP dengan sistem kapitasi. 
Membayar pemberi pelayanan kesehatan (PPK) dengan menggunakan sistem kapitasi berarti PPK dibayar di muka (praupaya) per bulan berdasarkan pada jumlah peserta yang terdaftar, tidak tergantung berdasarkan jumlah pelayanan yang diberikan. Konsep kapitasi merupakan sebuah konsep atau sistem pembagian berdasarakan jumlah orang yang menjadi tugas PPK untuk melayani dalam sebuah fasilitas kesehatan dengan memberi imbalan jasa kepada PPK dengan jumlah yang tetap, tanpa memperhatikan jumlah kunjungan, pemeriksaan, tindakan, obat, dan pelayanan medik lain yang diberikan oleh PPK tersebut (Wintera dan Hendrartini, 2005).

BPJS Kesehatan melakukan perubahan pola sistem kapitasi menjadi pembayaran kapitasi berbasis pemenuhan komitmen pelayanan kepada FKTP, pola ini diatur dalam Peraturan BPJS Kesehatan No 2 Tahun 2015, dan mulai diberlakukan per 1 Januari 2017. Dalam pengelolaan dana kapitasi di Klinik Kimia Farma 125 Denpasar, sebesar 65\% dari dana kapitasi digunakan untuk operasional klinik, dan sebesar 35\% dana kapitasi akan diterima oleh dokter umum dan gigi yang dihitung sesuai dengan formulasi yang telah disepakati. Adanya perubahan pola pembayaran kapitasi tentunya akan mendapatkan berbagai macam persepsi dokter umum sebagai PPK di FKTP Klinik Kimia Farma 125 Denpasar. Persepsi ini penting untuk diketahui karena akan mempengaruhi perilaku yang akan diberikan oleh dokter umum terhadap pasien JKN. Berdasarkan rumusan tersebut, peneliti tertarik untuk meneliti persepsi dokter umum terhadap sistem kapitasi berbasis pemenuhan komitmen pelayanan di FKTP Klinik Kimia Farma 125 Denpasar.

\section{METODE PENELITIAN}

Penelitian ini termasuk dalam penelitian deskriptif kualitatif, dimana penelitian ini menjelaskan bagaimana fenomena - fenomena yang ditemukan peneliti selama proses penelitian dilaksanakan. Hasil penelitian ditampilkan apa adanya tanpa dilakukan analisis lebih lanjut untuk mengetahui bagaimana fenomena itu terjadi (Sastroasmoro dan Ismael, 2011). Penelitian ini dilaksanakan di Klinik Kimia Farma 125 Denpasar, Jalan Diponegoro No 125 Denpasar. Waktu penelitian dilaksanakan pada Bulan Mei - Juli 2017.

Informan dalam penelitian ini sekaligus bertindak sebagai informan kunci yaitu dokter umum di Klinik Kimia Farma 125 Denpasar sebanyak 8 orang. Teknik pengambilan informan dalam penelitian ini dilakukan dengan teknik purposive sampling. Data yang digunakan dalam penelitian ini adalah data primer yang didapatkan dari hasil wawancara mendalam (indepth interview).

\section{HASIL}

\section{Gambaran Umum Lokasi Penelitian}

Klinik Kimia Farma 125 Denpasar merupakan klinik pratama swasta yang berlokasi di Jl Diponegoro No 125 Denpasar. Klinik Kimia Farma 125 Denpasar menerima pasien umum dengan cara pembayaran fee for service, peserta asuransi swasta yang telah bekerjasama, pasien perusahaan dengan sistem reimbursement dan peserta BPJS Kesehatan dengan cara pembayaran kapitasi. Klinik Kimia Farma 125 Denpasar mulai bekerjasama dengan BPJS Kesehatan pada 1 Januari 2014. Per Juni 2017 jumlah peserta BPJS Kesehatan yang terdaftar sebanyak 53.958 orang. Pelayanan yang diberikan kepada pasien BPJS Kesehatan diantaranya pelayanan medis dasar di PPK 1, pelayanan program rujuk balik, pelayanan 
prolanis, pelayanan dokter gigi, pelayanan penunjang laboratorium standar, dan pelayanan obat sesuai formularium nasional.

Besaran angka kontak (AK) yang ada di Klinik Kimia Farma 125 Denpasar pada bulan Mei 2017 sebesar 110,75 \%o, masih belum memenuhi zona aman. Besaran Rasio Rujukan Rawat Jalan Kasus Non Spesialistik (RRNS) sebesar 0,49 \% berada dalam zona aman. Besaran Rasio Peserta Prolanis Rutin Berkunjung (RPPB) 100 \% yang berada dalam zona prestasi.

\section{Karakteristik informan}

Berdasarkan Tabel 5.1, dapat digambarkan bahwa informan yang terlibat dalam penelitian ini sebanyak delapan orang, terdiri dari empat orang laki laki dan empat orang perempuan. Empat orang memiliki pengalaman praktek antara 1 hingga 5 tahun, dan empat orang memiliki pengalaman praktek lebih dari 5 tahun. Usia informan berkisar 26 40 tahun. Latar belakang pendidikan yang dimiliki informan sama, yaitu pendidikan dokter.

Tabel 1. Karakteristik Informan

\begin{tabular}{|c|c|c|c|}
\hline $\begin{array}{c}\text { Kode } \\
\text { Informan }\end{array}$ & $\begin{array}{c}\text { Jenis } \\
\text { Kelamin }\end{array}$ & $\begin{array}{c}\text { Pengalaman } \\
\text { Praktek }\end{array}$ & Status \\
\hline Informan 1 & $\mathrm{~L}$ & 10 tahun & Menikah \\
\hline Informan 2 & $\mathrm{P}$ & 9 tahun & Menikah \\
\hline Informan 3 & $\mathrm{~L}$ & 2 tahun & $\begin{array}{l}\text { Belum } \\
\text { Menikah }\end{array}$ \\
\hline Informan 4 & $\mathrm{~L}$ & 10 tahun & Menikah \\
\hline Informan 5 & $\mathrm{P}$ & 14 tahun & Menikah \\
\hline Informan 6 & $\mathrm{~L}$ & 1,5 tahun & $\begin{array}{l}\text { Belum } \\
\text { Menikah }\end{array}$ \\
\hline Informan 7 & $\mathrm{P}$ & 4 tahun & $\begin{array}{l}\text { Belum } \\
\text { Menikah }\end{array}$ \\
\hline Informan 8 & $\mathrm{P}$ & 2 tahun & $\begin{array}{l}\text { Belum } \\
\text { Menikah }\end{array}$ \\
\hline
\end{tabular}

Hasil Wawancara Penelitian
Hasil wawancara mendalam untuk mengetahui persepsi dokter umum terhadap sistem kapitasi JKN berbasis pemenuhan komitmen pelayanan di FKTP Klinik Kimia Farma 125 Denpasar diperoleh dari informan yang terdiri dari dokter umum yang bertugas di Klinik Kimia Farma 125 Denpasar. Hasil wawancara mendalam yang diperoleh peneliti berupa kutipan wawancara yang dikelompokkan sesuai dengan tema pada setiap variabel penelitian.

\section{Persepsi dokter umum terhadap besaran tarif kapitasi \\ Berdasarkan hasil wawancara, dokter} umum merasa sistem kapitasi yang dilakukan dalam era JKN sudah berjalan dengan baik. Sistem kapitasi yang dilakukan dalam era JKN selama ini dalam hal perhitungan dan pembayarannya selalu tepat waktu. Berikut hasil wawancara kepada informan :

"ee kalo dibilang sudah sesuai sih katanya cukup ya, kita sih cukup, cuma kedepannya jumlahnya perlu ditingkatkan karna kan kita juga ditekan untuk mengadakan berbagai program promotif dan preventif"

(Informan 1)

\section{Persepsi dokter umum terhadap standar pelayanan}

Semua peserta JKN berhak memperoleh pelayanan kesehatan yang mencakup pelayanan promotif, preventif, kuratif, dan rehabilitatif termasuk pelayanan obat dan bahan medis habis pakai sesuai dengan kebutuhan medis yang diperlukan. Berikut hasil wawancara kepada informan :

"ada peningkatan kunjungan drastis sekali, makin banyak peserta makin banyak kontak, mau gak mau pelayanan harus dimaksimalkan, kaya kita sekarang 
Arc. Com. Health • Juni 2019

ISSN: 2527-3620

jadinya 3 poli pagi sore, biar pasien gak ngeluh" (Informan 4)

"standar nya kita ikutin peraturan BPJS, kendala di p-care sering terganggu, loadingnya lama, selain itu pengetahuan masyarakat masih minim jadi harus dijelasin satu satu gimana cara manfaatin BPJS" (Informan 1)

\section{Persepsi dokter umum terhadap upaya komitmen pelayanan}

Peraturan BPJS Kesehatan No 2 Tahun 2015 mengatur kapitasi berbasis pemenuhan komitmen pelayanan untuk meningkatkan mutu pelayanan melalui pencapaian indikator pelayanan yang disepakati. Adapun hasil wawancara mendalam sebagai berikut :

"menurut saya bagus sih ya, jadi kita semakin meningkatkan mutu, berusaha biar kliniknya bagus, kalo pasiennya puas biar kita gak di blacklist sama pasien" (Informan 5)

\section{Persepsi dokter umum terhadap penilaian} indikator komitmen pelayanan

Indikator komitmen pelayanan yang dinilai BPJS Kesehatan diatur dalam Peraturan BPJS No 2 tahun 2015 terdiri dari beberapa indikator, diantaranya indikator angka kontak, rasio rujukan rawat jalan kasus non spesialistik (RRNS) dan rasio peserta prolanis berkunjung (RPPB). Indikator tersebut di evaluasi setiap bulan, dimana faskes diminta untuk membuat laporan indikator tersebut. Dari indikator tersebut dapat dilihat bagaimana pelayanan di suatu faskes. Berikut hasil wawancara kepada informan :

"agak berat juga buat menuhin angka kontak, soalnya 1 pasien walaupun dateng berkali kali di
Vol. 6 No. $1: 18-24$

itung nya 1 kali kontak, pernah kita gak mencapai, gak lulus di angka kontak" (Informan 1)

"saya merasa kalo kurang pas jika kita harus menuhin target angka kontak, kan agak aneh sama tujuan untuk menurunkan angka kesakitan, kenapa malah disuruh menuhin angka kontak? Selama ini pasien yang dateng selalu sakit, belum ada yang gak sakit tapi periksa, jadi kesannya kaya disuruh banyak yang sakit" (Informan 3)

\section{DISKUSI}

\section{Persepsi dokter umum terhadap besaran tarif kapitasi}

Besarnya kapitasi yang ditetapkan oleh BPJS Kesehatan sudah diperhitungkan untuk mencukupi biaya opersional pelayanan kesehatan di FKTP. Karena sistem pembayaran kapitasi ditentukan oleh banyaknya jumlah peserta, semakin banyak jumlah peserta yang terdaftar, maka akan semakin banyak pula kapitasi yang akan dibayarkan. Sebagian besar dokter umum menganggap besaran kapitasi yang diterima sudah cukup untuk memberikan pelayanan kepada peserta JKN yang terdaftar. Informan menyatakan setuju dengan besaran kapitasi yang diterapkan oleh BPJS Kesehatan. Hal ini sesuai dengan hasil penelitian Sugiarto, Hendrartini dan Mukti (2003) menyatakan bahwa persepsi stakeholders dalam hal ini kepala puskesmas tentang sistem kapitasi sangat positif. Pola ini dirasakan mampu melakukan kendali biaya pelayanan kesehatan. Pola kapitasi yang berpusat pada PPK I dan bukan di kabupaten akan menekan biaya dan memaksimalkan pelayanan.

\section{Persepsi dokter umum terhadap standar pelayanan}

Standar pelayanan kesehatan yang diberikan oleh dokter hendaknya mengikuti aturan yang diberikan oleh BPJS Kesehatan. 
standar pelayanan ini diperlukan untuk menjaga kualitas layanan dan memberikan pelayanan kesehatan yang efektif untuk pasien dan efisien untuk penyedia layanan. Pelayanan kesehatan memiliki alur dan prosedur yang harus diketahui dan ditaati oleh pasien JKN. Kelengkapan persyaratan administrasi akan mempengaruhi cepat atau lambatnya proses pelayanan kesehatan. Dalam pengamatan peneliti, hal tersebut dicoba diatasi dengan memasang alur pelayanan, syarat mendapatkan pelayanan, dan informasi lainnya di dinding depan klinik dan dinding ruang tunggu. Selain itu, dilakukan juga penjelasan mengenai penggunaan kartu saat pasien memeriksakan dirinya ke klinik. Peran FKTP dalam pelayanan kesehatan berjenjang yaitu sebagai gate keeper. Gate keeper memiliki fungsi diantaranya sebagai kontak pelayanan pertama. FKTP merupakan tempat pertama yang akan dikunjungi pasien setiap kali mendapat masalah kesehatan. Saat pasien ditangani di FKTP, dokter memiliki peranan yang penting dalam koordinasi pelayanan dengan penyelenggara kesehatan lainnya dalam memberi pelayanan kesehatan sesuai kebutuhan pasien. Tugas dokter disini sebagai pengatur pelayanan (care manager) agar rasio rujukan dapat terkendali dan pasien merasa mendapatkan pelayanan kesehatan yang sesuai dengan kebutuhannya.

\section{Persepsi dokter umum terhadap upaya komitmen pelayanan}

Peraturan BPJS Kesehatan No 2 Tahun 2015 mengatur kapitasi berbasis pemenuhan komitmen pelayanan untuk meningkatkan mutu pelayanan melalui pencapaian indikator pelayanan yang disepakati. Terkait upaya komitmen pelayanan, penelitian ini menyatakan informan setuju dalam memberikan pelayanan kesehatan diperlukan upaya dalam meningkatkan mutu pelayanan. Hasil penelitian ini didukung oleh Wahyuningsih (2009) yang menyatakan ada beberapa faktor yang menjadi patokan sebuah fasilitas kesehatan baik milik pemerintah atau swasta dapat menjadi fasilitas kesehatan yang baik dan dapat memuaskan konsumennya yaitu tarif, dokter dan perawat, pelayanan, fasilitas dan pemasaran. Jika salah satu tidak terpenuhi atau kurang baik dibandingkan fasilitas kesehatan lain maka akan berdampak kepada fasilitas kesehatan itu sendiri dan menjadi penilaian untuk para konsumen untuk memilih fasilitas kesehatan yang terbaik. Informan setuju untuk memuaskan pasien terhadap pelayanan kesehatan yang diberikan, dokter harus meningkatkan mutu pelayanan yang diberikan.

Klinik Kimia Farma 125 Denpasar berkomitmen meningkatkan mutu pelayanan melalui perbaikan indikator yang ditentukan oleh BPJS Kesehatan. Upaya untuk meningkatkan mutu pelayanan dapat dilihat dari hasil penilaian dengan mempertimbangkan beberapa hal, mulai dari ketersediaan sumber daya, kelengkapan sarana dan prasarana yang sesuai dengan lingkup pelayanan, dan waktu pelayanan yang diberikan.

Dalam pengamatan peneliti, Klinik Kimia Farma 125 Denpasar secara umum dalam memberikan pelayanan kesehatan kepada peserta JKN sudah sesuai dengan standar yang ditentukan BPJS Kesehatan. Namun terdapat beberapa sarana dan prasarana yang tersedia saat ini belum memenuhi kebutuhan pasien. Dapat dilihat dari kurangnya kapasitas tempat duduk di ruang tunggu hingga menyebabkan pasien tidak mendapatkan tempat duduk. Kurangnya fasilitas tersebut terjadi pada jam 
Arc. Com. Health • Juni 2019

ISSN: 2527-3620

ramai sekitar pukul $08.00-12.00$, dan $17.00-$ 21.00 .

\section{Persepsi dokter umum terhadap penilaian indikator komitmen pelayanan}

Informan melakukan beberapa upaya untuk mencapai target indikator pelayanan. Upaya yang dilakukan informan diantaranya meningkatkan angka kontak dengan promosi program skrining papsmear dan pemeriksaan payudara secara onsite di perusahaan yang karyawannya sebagai peserta BPJS Kesehatan, mengadakan kegiatan senam bersama dan edukasi kesehatan, dan meningkatkan kualitas pelayanan kesehatan. Upaya ini sesuai dengan anjuran dalam peraturan bersama Sekretaris Jenderal Kementerian Kesehatan Republik Indonesia dengan BPJS Kesehatan No 2 Tahun 2017, dimana dalam rangka meningkatkan dan memudahkan akses pelayanan luar gedung, tenaga FKTP harus memiliki data peserta yang terdaftar di FKTP untuk melakukan perencanaan pelayanan luar gedung. Pelayanan luar gedung ini bertujuan untuk meningkatkan indikator angka kontak sebuah FKTP.

Indikator komitmen pelayanan harus diperhatikan karena indikator ini dapat menjadi dasar penentuan besaran kapitasi yang akan diberikan kepada provider BPJS Kesehatan. Terkait dari hasil wawancara pada informan, dokter meningkatkan mutu pelayanan untuk mencapai indikator pelayanan yang ditentukan. Selain bertujuan meningkatkan mutu pelayanan, dokter juga mengharapkan adanya penghargaan yang diberikan oleh BPJS Kesehatan. Informan juga berharap ada perhatian dari BPJS Kesehatan kepada FKTP yang telah berkerjasama sejak lama. Perhatian seperti adanya pelatihan dan pemeliharaan faskes agar faskes dapat meningkatkan lagi kualitas pelayanannya.
Vol. 6 No. $1: 18-24$

Peraturan BPJS Kesehatan No 2 Tahun 2015 pasal 36 menyatakan hasil pencapaian target indikator komitmen pelayanan FKTP menjadi dasar pembayaran kapitasi berbasis pemenuhan komitmen pelayanan. FKTP yang tidak memenuhi seluruh target indikator komitmen pelayanan pada zona aman, menerima pembayaran kapitasi sebesar $75 \%$ dari norma kapitasi yang ditetapkan. Apabila FKTP dapat memenuhi 3 indikator komitmen pelayanan zona prestasi yang berlangsung selama 6 bulan berturut - turut, kompensasi kepada FKTP diberikan dalam bentuk peningkatan kompetensi melalui pelatihan untuk meningkatkan kompetensi dan performa FKTP.

\section{SIMPULAN}

Persepsi dokter umum terhadap sistem kapitasi berbasis pemenuhan komitmen pelayanan di FKTP Klinik Kimia Farma 125 Denpasar dapat disimpulkan sebagai berikut Sebagian besar dokter umum setuju bahwa besaran tarif kapitasi yang diberikan oleh BPJS Kesehatan cukup untuk melaksanakan pelayanan kesehatan di FKTP Klinik Kimia Farma 125 Denpasar. Dokter merasa adanya peningkatan kesejahteraan yang dirasakan setelah ikut bergabung sebagai provider BPJS Kesehatan. Dokter umum melaksanakan pelayanan kesehatan di FKTP sesuai dengan ketentuan dan berpedoman pada 110 penyakit yang harus diselesaikan di FKTP. Namun terdapat beberapa kasus yang akan dirujuk apabila fasilitas tidak mendukung walaupun kasus tersebut harus diselesaikan di FKTP. Untuk pasien dengan kasus yang bisa diselesaikan di FKTP namun setelah pengobatan beberapa kali tidak kunjung sembuh, maka akan di rujuk ke FKTRL sesuai dengan spesialistiknya dengan catatan tertentu. 
Arc. Com. Health Juni 2019

ISSN: 2527-3620

Untuk mendukung upaya komitmen pelayanan yang diberlakukan BPJS Kesehatan, dokter umum telah mendapatkan sosialisasi dari BPJS Kesehatan. Dalam pelaksanaannya dokter memberikan pelayanan yang lebih baik dengan menambahkan poli untuk mempercepat waktu antrian. Dalam memenuhi penilaian indikator komitmen pelayanan, dokter sepakat untuk meningkatkan angka kontak, angka RRNS dan angka RPPB agar sesuai dengan standar yang ditetapkan BPJS Kesehatan. Dokter juga berupaya untuk lebih mengajak masyarakat untuk memanfaatkan kartu BPJS Kesehatannya di FKTP. Dokter sepakat penilaian indikator komitmen pelayanan dapat memberikan motivasi dalam meningkatkan kualitas layanan.

\section{DAFTAR PUSTAKA}

Badan Penyelenggara Jaminan Sosial Kesehatan. (2015). Peraturan No 2 Tahun 2015 tentang Norma Penetapan Besaran Kapitasi dan Pembayaran Kapitasi Berbasis Pemenuhan Komitmen Pelayanan pada Fasilitas Kesehatan Tingkat Pertama. Jakarta : BPJS Kesehatan

Sastroasmoro \& S. Ismael. (2011). Dasar - Dasar Metodologi Penelitian Klinis Edisi 4. Jakarta : Sagung Seto

Sekretaris Jenderal Menteri Kesehatan RI dan BPJS Kesehatan. (2017). Peraturan No 2 Tahun 2017 tentang Petunjuk Teknis Pelaksanaan Pembayaran Sistem Kapitasi Berbasis Pemenuhan Komitmen Pelayanan Pada Fasilitas Tingkat Pertama. Jakarta : BPJS Kesehatan

Sekretariat Negara. (2004). Undang-Undang No 40 tentang Sistem Jaminan Sosial Nasional. Jakarta : Sekretariat Negara

Sugiarto, Hendrartini \& Mukti. (2003). Persepsi Stakeholder Terhadap Perubahan Pola Kapitasi
Vol. 6 No. $1: 18-24$

Total Biaya Pelayanan Kesehatan Peserta Wajib PT Askes Dari Basis Kabupaten Ke Basis Puskesmas Di Kabupaten Kulonprogo. Yogyakarta : Jurnal Manajemen Pelayanan Kesehatan Vol. 6 No. 04/2003 FK UGM

Wahyuningsih, N. (2008). Analisis Lost Patient di Poliklinik Rawat Jalan Rumah Sakit Pertamina Jaya Tahun 2008. Jakarta : Universitas Indonesia

Wintera \& Hendrartini. (2005). Determinan Kepuasan Dokter Puskesmas Terhadap Sistem Pembayaran Kapitasi Peserta Wajib PT Askes di Kabupaten Donggala Provinsi Sulawesi Tengah. JMPK Vol. 08/No.2/Juni/2005 